\title{
Características morfológicas e culinárias de etnovariedades de mandioca de mesa em diferentes épocas de colheita
}

\author{
Morphological characteristics and culinary quality of cassava \\ ethnovarieties at different harvesting times
}

\begin{abstract}
Eliane Cristina Moreno de Pedri ${ }^{1 *}$, Ana Aparecida Bandini Rossi ${ }^{1}$, Elisa dos Santos Cardoso ${ }^{1}$, Auana Vicente Tiago', Eulália Soler Sobreira Hoogerheide ${ }^{2}$, Oscar Mitsuo Yamashita' ${ }^{1}$

${ }_{1}^{1}$ Universidade do Estado de Mato Grosso (UNEMAT), Faculdade de Ciências Biológicas e Agrárias, Alta Floresta/MT - Brasil

2 Embrapa Agrossilvipastoril, Sinop/MT - Brasil
\end{abstract}

\section{*Corresponding Author}

Eliane Cristina Moreno de Pedri, Universidade do Estado de Mato Grosso (UNEMAT), Faculdade de Ciências Biológicas e Agrárias, Av. Perimetral Rogério Silva, s/n, Jardim Flamboyant, CEP: 78580-000, Alta Floresta/MT - Brasil, e-mail: elicmbio@gmail.com

Cite as: Morphological characteristics and culinary quality of cassava ethnovarieties at different harvesting. Braz. J. Food Technol., v. 21 , e2018073, 2018.

Received: Mar. 26, 2018; Accepted: July 09, 2018

\section{Resumo}

As raízes da mandioca são ricas em carboidratos e amplamente consumidas em todo o mundo. Objetivou-se, neste estudo, avaliar características morfológicas e culinárias de quatro etnovariedades de mandioca (Cacau branca, Cacau roxa, Cacau amarela e Mandioca pão), em diferentes épocas de colheita. As características avaliadas foram: forma da raiz, cor da película, textura da epiderme, cor do córtex, cor da polpa, descascamento da película e do córtex, tempo de cozimento, padrão de massa cozida e deterioração pós-colheita das raízes. As etnovariedades exibiram variação fenotípica quanto às características morfológicas. A Cacau branca e a Cacau roxa apresentaram descascamento fácil nas três primeiras épocas de colheita. O tempo de cocção variou de 'bom' a 'ruim' entre as etnovariedades, sendo que a Cacau roxa apresentou o menor tempo de cozimento (15 min), aos seis meses, e a Cacau amarela, o maior tempo (35 min), aos 10 e 12 meses. A Cacau branca e a Cacau roxa apresentaram maior nota média quanto à classificação de massa cozida, sendo as mais indicadas para utilização como mandioca de mesa. Quanto às características 'tempo de cocção' e 'qualidade da massa cozida', as raízes das quatro etnovariedades, colhidas aos seis e oito meses pós-plantio, apresentaram-se ideais para o consumo de mesa. O tempo de cozimento apresentou aumento crescente de acordo com a permanência das plantas no campo. As etnovariedades Cacau amarela e Mandioca pão são as mais indicadas para cultivos que visem à comercialização, pois apresentaram, em todas as épocas de colheita, menor susceptibilidade à deterioração.

Palavras-chave: Cocção; Descascamento; Deterioração pós-colheita; Manihot esculenta; Massa cozida; Textura.

\section{Abstract}

Cassava roots are rich in carbohydrates and widely consumed throughout the world. The objective of this study was to evaluate the morphological and culinary characteristics of four cassava ethnovarieties (Cacau branca, Cacau roxa, Cacau amarela and Mandioca pão) at different harvesting times. The characteristics evaluated were: root shape, peel colour, epidermis texture, cortex colour, pulp colour, removal of the peel and cortex, cooking time, standard cooked mass and post-harvest root deterioration. The ethnovarieties exhibited phenotypic variation of the morphological characteristics. Cacau branca and Cacau roxa were easy to peel in the first three harvesting seasons. The cooking time ranged from 'good' to 'bad' amongst the ethnovarieties, Cacau roxa showing the shortest cooking time (15 min) in the sixth month and Cacau amarela showing the longest cooking time (35 min) in the tenth and twelfth months of harvest. Cacau branca and Cacau roxa showed high average values for cooked mass, showing that they were more suitable for use as table cassava. As for the cooking time and cooked mass quality, the roots of the four ethnovarieties, harvested in the six and eight months after planting, were ideal for table consumption. The cooking time increased according to the permanence of the plants in the field. The Cacau amarela and Mandioca pão ethnovarieties were the most suitable for commercial crops because they showed lower susceptibility to deterioration in all harvest seasons.

Keywords: Cooking; Peeling; Post-harvest deterioration; Manihot esculenta; Cooked mass; Texture. 


\section{Introdução}

A mandioca (Manihot esculenta Crantz), também conhecida por mandioca de mesa, macaxeira ou aipim, apresenta um alto teor energético e exerce importante papel na dieta alimentar. No Brasil, a espécie é comumente cultivada por agricultores familiares que têm, nesta atividade, uma importante fonte de renda, e desempenham papel de destaque na conservação da espécie (CHISTÉ; COHEN, 2006; FARALDO et al., 2000).

As etnovariedades de mandioca recebem diferentes nomes de acordo com a localidade em que são cultivadas; por isso, é importante caracterizá-las, sendo os descritores morfológicos uma ferramenta muito utilizada na identificação e diferenciação fenotípica dessas espécies, uma vez que fornecem informações sobre parentais e genótipos com potencial para utilização em cruzamentos, evitando duplicações de acessos nos bancos de germoplasma (GUSMÃO; MENDES NETO, 2008). Outra característica importante a ser analisada na mandioca é a qualidade culinária, pois esta apresenta fatores que interferem diretamente na maioria das receitas preparadas a partir de suas raízes.

A qualidade culinária de raízes frescas de mandioca é um importante parâmetro, que envolve fatores variados e complexos por se constituírem de um conjunto de características físicas, químicas e sensoriais; algumas dessas características são determinadas objetivamente, como compostos cianogênicos, amido, fibra e tempo de cocção, e outras, subjetivamente, como sabor, consistência e textura da massa cozida (WHEATLEY, 1987). Tendo em vista que além do consumo in natura, principal forma de utilização na alimentação humana, os produtos industrializados a partir da massa cozida, como coxinhas, croquetes, empanados e fritas tipo chips, vêm ganhando espaço no comércio brasileiro (FENIMAN, 2004).

O tempo de cozimento e o padrão da massa cozida são fatores observados pelo consumidor, por interferirem na maioria dos produtos preparados a partir das raízes de mandioca (PEREIRA et al., 1985), e, como frequentemente abordado, quanto menor o tempo de cocção, melhor a qualidade da massa obtida (LORENZI, 1994; WHEATLEY; GOMEZ, 1985). Raízes de boa qualidade culinária apresentam massa cozida que deve ser facilmente esmagada e desfeita quando amassada com um garfo, formando uma pasta de textura farinácea, consistência plástica e moldável (BORGES et al., 1992).

A variação no tempo de cozimento e na qualidade da massa cozida é fator inibidor para o comércio de raízes de mandioca durante todo o ano. Estas características apresentam variações entre raízes de uma mesma planta e também conforme o tipo de solo, a variedade e a idade da planta (BORGES et al., 2002). Estudos constataram variação do tempo de cozimento em função da época de colheita, da região de plantio e do genótipo (VÍTOR et al., 2015; OLIVEIRA et al., 2010; VIEIRA et al., 2009; LORENZI, 1994).

A comercialização e o consumo de raízes frescas de mandioca, principalmente nos centros urbanos, também são afetados pela dificuldade do descascamento das raízes e pela rápida deterioração pós-colheita (OLIVEIRA et al., 2005). A deterioração pós-colheita gera preocupação para os produtores devido à alta perecibilidade das raízes de mandioca. Os danos iniciam-se durante as primeiras 24 horas após a colheita, levando a perdas quantitativas. Os fatores apontados como responsáveis pela deterioração são fisiológicos e microbiológicos, e causam, respectivamente, o escurecimento vascular dos tecidos e a decomposição das raízes (HENRIQUE et al., 2010; BOOTH, 1976).

Diante do exposto, objetivou-se, neste estudo, avaliar as características morfológicas e culinárias de quatro etnovariedades de mandioca, em quatro épocas de colheita, nas condições edafoclimáticas do munícipio de Alta Floresta, Mato Grosso, Brasil.

\section{Material e métodos}

O experimento, conduzido na Chácara Nossa Senhora Aparecida (957'00,8'S, 5605'44,4"W, altitude média de 304 m), na Comunidade Central, município de Alta Floresta, Mato Grosso, foi instalado em Latossolo Vermelho-amarelo distrófico (EMBRAPA, 2013). O clima da região é do tipo Am, com estação chuvosa e seca, temperatura média entre $23^{\circ} \mathrm{C}$ e $29^{\circ} \mathrm{C}$, e precipitação anual variando entre 2.500 e $3.100 \mathrm{~mm}$ (ALVARES et al., 2013).

A análise química do solo, baseada em amostras coletadas em profundidade de 0 a $10 \mathrm{~cm}$, foi realizada no Laboratório de Análise de Solos, Adubos e Foliar (LASAF) da Universidade do Estado de Mato Grosso (UNEMAT), Campus Universitário de Alta Floresta (Tabela 1).

No preparo do solo da área experimental, foram realizadas as operações de aração, gradagem, alinhamento e abertura manual das covas. Em função da análise química do solo, foram realizadas calagem e adubação (aplicação no sulco de plantio: 80 g de calcário dolomítico e $20 \mathrm{~g}$ do formulado contendo superfosfato simples e cloreto de potássio), para correção da acidez do solo e fornecimento de nutrientes, seguindo recomendações propostas por Ribeiro et al. (1999).

As etnovariedades avaliadas neste estudo foram: Cacau branca (CB), Cacau roxa (CR), Cacau amarela (CA) e Mandioca pão (MP). O experimento foi implantado em setembro de 2016, em uma área total de $1.200 \mathrm{~m}^{2}$, utilizando-se manivas de 2 a $3 \mathrm{~cm}$ de diâmetro, com 5 a 7 gemas, e comprimento médio de $20 \mathrm{~cm}$. O espaçamento adotado foi 1,0 m entre plantas e 1,2 m entre linhas.

O delineamento experimental utilizado foi o de blocos ao acaso com quatro repetições e os tratamentos 
Tabela 1. Resultados das análises químicas do solo da área experimental.

\begin{tabular}{|c|c|c|c|c|c|c|c|c|c|}
\hline \multicolumn{2}{|c|}{$\mathbf{P h}$} & $\mathbf{P}$ & K & $\mathrm{Ca}^{+2}$ & $\mathrm{Mg}^{+2}$ & $\mathrm{~K}^{+}$ & $\mathrm{Al}^{+3}+\mathrm{H}^{+}$ & $\mathbf{A l}^{+3}$ & \multirow[t]{2}{*}{$\mathrm{H}^{+}$} \\
\hline $\mathrm{H}_{2} \mathrm{O}$ & $\mathrm{CaCl}_{2}$ & \multicolumn{2}{|c|}{$--\mathrm{mg} / \mathrm{dm}^{-3--}$} & \multicolumn{5}{|c|}{ - } & \\
\hline 5,1 & 4,4 & 1,9 & 21,1 & 0,71 & 0,39 & 0,05 & 5,35 & 0,44 & 4,91 \\
\hline \multicolumn{4}{|c|}{ Areia (\%) } & \multicolumn{2}{|c|}{ Silte (\%) } & \multicolumn{4}{|c|}{ Argila (\%) } \\
\hline \multicolumn{4}{|c|}{39,6} & \multicolumn{2}{|c|}{5,0} & \multicolumn{4}{|c|}{55,4} \\
\hline
\end{tabular}

foram arranjados segundo o esquema de parcelas e subparcelas, sendo as parcelas constituídas por quatro etnovariedades (CB, CR, CA e MP) e as subparcelas, por quatro épocas de colheita (seis, oito, 10 e 12 meses pós-plantio). Em cada época, foram avaliadas 24 plantas por etnovariedade, selecionando-se raízes de padrão comercial para caracterização morfológica e avaliação culinária. Em seguida, as mesmas foram lavadas em água corrente, à sombra, para remoção de sujidades.

No período de condução do experimento, foram registradas temperaturas médias máximas e mínimas de $32{ }^{\circ} \mathrm{C}$ e $21^{\circ} \mathrm{C}$, respectivamente, com precipitação média anual de $2.169 \mathrm{~mm}$ (Figura 1).

\subsection{Características morfológicas das raízes}

A caracterização morfológica das raízes foi realizada em cada época de colheita e em 24 plantas de cada etnovariedade, sendo avaliadas as seguintes características: formato da raiz (cônico, cônico-cilíndrico, cilíndrico ou irregular), textura da epiderme da raiz (lisa ou rugosa), cor da película da raiz (branco ou creme, amarelo, marrom claro e marrom escuro), cor do córtex da raiz (branco ou creme, amarelo, rosado e roxo) e a cor da polpa da raiz (branca, creme, amarela e rosada), seguindo classificação proposta por Fukuda e Guevara (1998).

\subsection{Características culinárias}

Para a avaliação do descascamento, selecionaram-se aleatoriamente cinco raízes comerciais de cada etnovariedade, em cada época de colheita. Da porção mediana das raízes foram retirados 10 cilindros, sendo estes descascados manualmente, com auxílio de uma faca, e avaliados quanto à capacidade de a película se destacar do córtex e de o córtex se destacar da polpa (Figura 2).

O descascamento foi classificado em: fácil (quando a película e córtex destacam-se de modo fácil e uniforme, quando puxada com a faca, sendo retiradas inteiras); mediano (quando a casca se solta com alguma dificuldade, quando puxada com a mão, ocorrendo maior presença de fragmentos que permanecem aderidos à polpa do que na classe anterior) e difícil (quando a casca está bastante aderida à polpa, quando puxada com a mão, quebra-se em pequenos pedaços que se destacam,

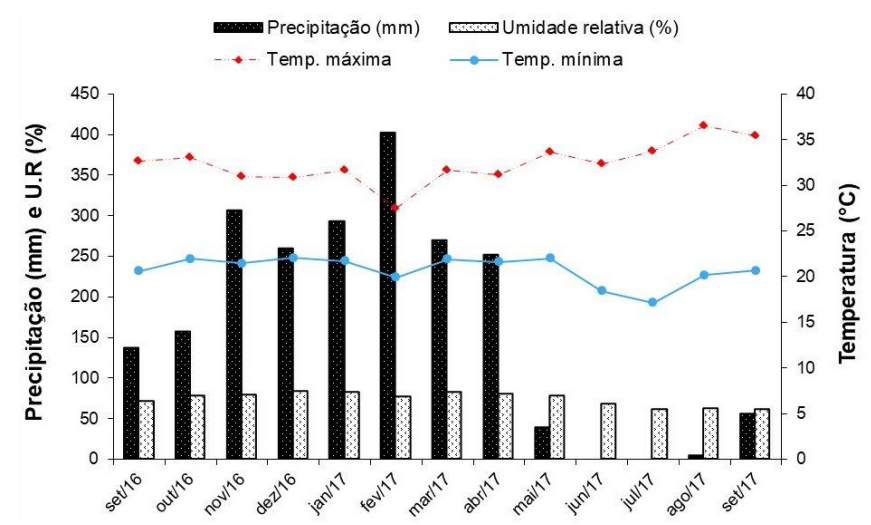

Figura 1. Médias mensais de precipitação $(\mathrm{mm})$, umidade relativa do ar (UR\%) e temperaturas máximas e mínimas $\left({ }^{\circ} \mathrm{C}\right)$, coletadas de setembro/2016 a setembro/2017, na Estação Meteorológica da UNEMAT, Campus de Alta Floresta, Mato Grosso.

permanecendo grande parte destes aderida à polpa) (OLIVEIRA et al., 2011; SOARES, 2011; PONTE, 2008).

O tempo de cozimento foi avaliado em uma amostra de cinco cilindros (250 g), com cerca de $5 \mathrm{~cm}$ de comprimento longitudinal, sendo preservado o diâmetro da raiz como peculiaridade de cada etnovariedade. Os cilindros foram retirados da porção mediana de cinco raízes comerciais representativas da subparcela.

As raízes foram colocadas em uma panela de aproximadamente $56 \mathrm{~cm}$ de diâmetro, com um litro de água fervendo $\left(98^{\circ} \mathrm{C}\right)$. A verificação do cozimento foi feita com um garfo e a raiz foi considerada cozida quando não mais oferecia resistência à penetração. Na avaliação, seguiu-se uma escala com quatro classes: cozimento ótimo (0 a 10 minutos); bom (11 a 20 minutos); regular (21 a 30 minutos) e ruim (> 30 minutos), conforme metodologia de Pereira et al. (1985).

Para avaliação do padrão de massa cozida, selecionaram-se aleatoriamente três pedaços cozidos de mandioca, os quais foram amassados vigorosamente com um garfo, por 30 vezes consecutivas, e mais 30 amassamentos sob pressão dos dedos contra a palma da mão. Em seguida, analisou-se a massa obtida quanto a textura, plasticidade visual e pegajosidade à mão (Tabela 2). 


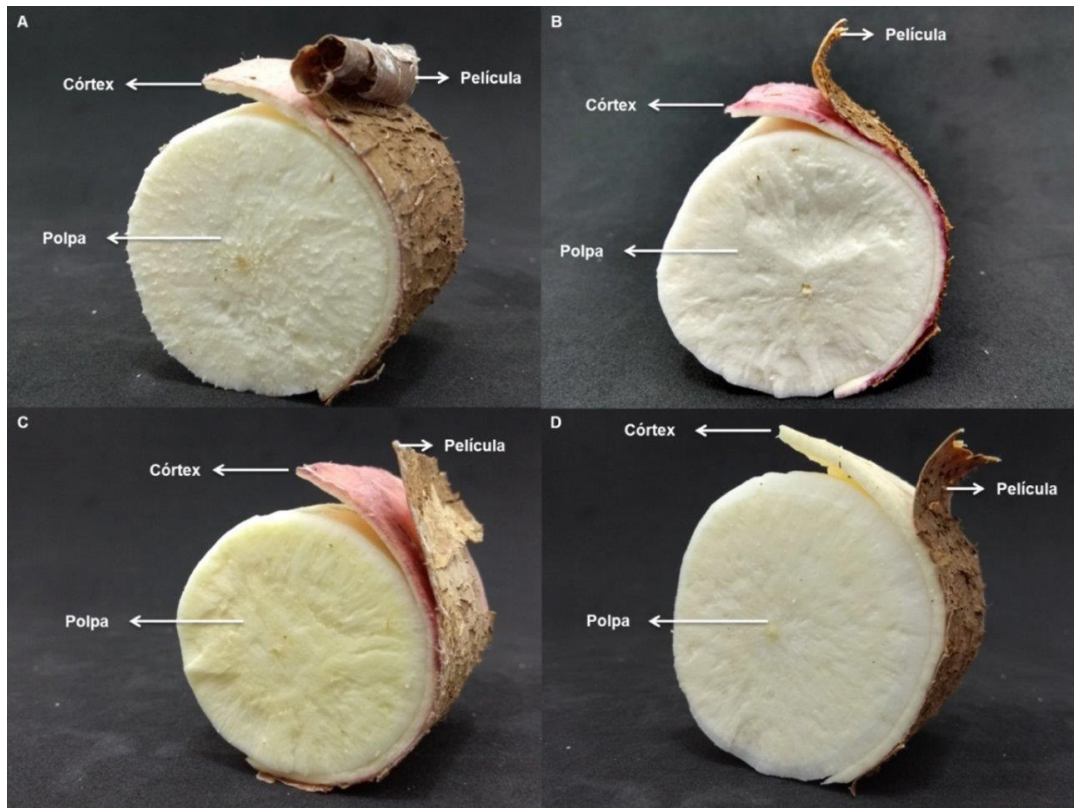

Figura 2. Detalhe para película, córtex e polpa das raízes das etnovariedades Cacau branca (A), Cacau roxa (B), Cacau amarela (C) e Mandioca pão (D).

Tabela 2. Escala de avaliação para padrão de massa cozida de mandioca.

\begin{tabular}{ccc} 
Padrão & Nota $^{(1)}$ & Classificação da massa \\
1 & 10 & Não encaroçada, plástica e não pegajosa \\
2 & 9 & Pouco encaroçada, plástica e não pegajosa \\
3 & 8 & Não encaroçada, ligeiramente plástica e não pegajosa \\
4 & 7 & Não encaroçada, não plástica e não pegajosa \\
5 & 6 & Não encaroçada, não plástica e pegajosa \\
6 & 5 & Muito encaroçada, plástica e pegajosa \\
7 & 4 & Muito encaroçada, não plástica e pegajosa \\
\hline
\end{tabular}

(1) Correspondente ao padrão, em ordem decrescente de qualidade. Fonte: Pereira et al. (1985).

\subsection{Deterioração das raízes pós-colheita}

Para verificação da deterioração das raízes de mandioca, após as colheitas, foram selecionadas cinco raízes de cada etnovariedade, representativas na subparcela, e estas foram dispostas em prateleira, em temperatura ambiente por quatro dias. Após este período, as raízes foram cortadas em pedaços de $3 \mathrm{~cm}$ de espessura e então avaliadas seguindo uma escala de notas proposta por Fukuda e Guevara (1998). Nessa escala, considera-se 1 (sem deterioração), 2 (até 20\% de raízes deterioradas), 3 (20 a 40\% de raízes deterioradas), 4 (41 a 60\% de raízes deterioradas) e 5 (mais de $60 \%$ de raízes deterioradas).

Os dados foram submetidos à análise de variância (ANOVA) e as médias comparadas pelo Teste de Tukey no nível de $5 \%$ de probabilidade. Para o fator época de colheita, foram ajustadas regressões polinomiais, sendo que a escolha do modelo foi feita com base no maior valor do coeficiente de determinação $\left(R^{2}\right)$. As análises estatísticas foram realizadas com auxílio do programa GENES v. 2018.23 (CRUZ, 2013).

\section{Resultados e discussão}

\subsection{Características morfológicas das raízes}

Constataram-se diferenças entre as quatro etnovariedades estudadas, exceto para a forma da raiz e para a textura da epiderme (Tabela 3).

Raízes com coloração externa branca e cor do córtex branco ou creme são ideais para a indústria, enquanto as com coloração externa marrom clara ou escura são preferidas para a produção de mandioca de mesa (VIEIRA et al., 2008). Portanto, as etnovariedades CB, CR e CA apresentam potencial para utilização para mesa e a MP, por apresentar córtex branco ou creme, pode também ser indicada para utilização em agroindústria de processamento (produção de farinha e fécula). 
Tabela 3. Caracterização morfológica das raízes tuberosas de quatro etnovariedades de mandioca, segundo os descritores propostos por Fukuda e Guevara (1998).

\begin{tabular}{ccccc}
\hline Características & Cacau branca & Cacau roxa & Cacau amarela & Mandioca pão \\
Forma da raiz & Cilíndrica & Cilíndrica & Cilíndrica & Cilíndrica \\
Cor da película & Marrom escuro & Marrom claro & Marrom claro & Marrom claro \\
Textura da epiderme & Rugosa & Rugosa & Rugosa & Rugosa \\
Cor do córtex & Roxo & Roxo & Rosado & Branco ou creme \\
Cor da polpa crua & Branca & Branca & Amarela & Branca \\
\hline
\end{tabular}

Tabela 4. Análise de descascamento das etnovariedades Cacau branca, Cacau roxa, Cacau amarela e Mandioca pão em quatro épocas de colheita.

\begin{tabular}{|c|c|c|c|c|c|c|c|c|}
\hline \multirow{2}{*}{$\begin{array}{l}\text { Época de } \\
\text { colheita }\end{array}$} & \multicolumn{2}{|c|}{ Cacau branca } & \multicolumn{2}{|c|}{ Cacau roxa } & \multicolumn{2}{|c|}{ Cacau amarela } & \multicolumn{2}{|c|}{ Mandioca pão } \\
\hline & Película & Córtex & Película & Córtex & Película & Córtex & Película & Córtex \\
\hline 6 meses & $\mathrm{F}$ & $\mathrm{F}$ & $\mathrm{F}$ & $\mathrm{F}$ & $\mathrm{F}$ & $\mathrm{F}$ & $\mathrm{F}$ & $\mathrm{F}$ \\
\hline 8 meses & $\mathrm{F}$ & $\mathrm{F}$ & $\mathrm{F}$ & $\mathrm{F}$ & $\mathrm{F}$ & $\mathrm{F}$ & $\mathrm{F}$ & M \\
\hline 10 meses & $\mathrm{F}$ & F & $\mathrm{F}$ & $\mathrm{F}$ & D & D & F & D \\
\hline 12 meses & D & D & D & $M$ & D & D & D & $M$ \\
\hline
\end{tabular}

$\mathrm{F}=$ fácil; $\mathrm{D}=$ difícil; $M=$ mediano

A polpa da raiz é a parte da mandioca mais importante e mais utilizada para o consumo humano. Das etnovariedades avaliadas, a cor branca foi constatada nas etnovariedades CB, CR e MP, enquanto a CA apresentou coloração amarelada, o que, de acordo com Silva et al. (2014), está relacionado a altos teores de carotenoides, com destaque para o $\beta$-caroteno. É importante observar que esse carotenoide, por ser precursor da vitamina A, representa um incremento nutricional.

\subsection{Descascamento das raízes}

Quanto ao descascamento, a CB e a CR destacaram-se entre as etnovariedades nas três primeiras épocas de colheita, por apresentar facilidade de destacar tanto a película quanto o córtex (Tabela 4). A CA apresentou facilidade para as raízes serem descascadas, película e córtex, nas duas primeiras épocas de colheita, e a MP, apenas aos seis meses de avaliação, fator considerado negativo na seleção de mandiocas para mesa (Tabela 5).

A facilidade em destacar o córtex das raízes de mandioca é muitas vezes associada à boa cocção, embora não tenham sido encontrados registros desta informação em literatura científica. Neste estudo, verificou-se uma relação entre a dificuldade de destaque do córtex da raiz com o tempo de cocção, com tendência para aumento no tempo de cozimento à medida que o descascamento se tornou mais difícil (Tabela 4; Figura 3). Conforme relato de alguns agricultores familiares, os mesmos fazem desta associação fator determinante na hora de selecionar e manter uma etnovariedade em suas roças.
Tabela 5. Resumo da análise de variância para o tempo de cocção das raízes de mandioca.

\begin{tabular}{ccc}
\hline Fonte de variação & GL & Quadrado Médio \\
\hline BLOCOS $(\mathrm{BL})$ & 4 & 188,09 \\
BL x ETNO & 12 & 2,64 \\
Época de colheita (EC) & 3 & $299,48^{\star *}$ \\
Etnovariedade (ETNO) & 3 & $489,48^{\star *}$ \\
ETNO x EC & 9 & $30,31^{\star *}$ \\
Erro & 48 & 2,63 \\
C.V. $(\%)=6,10$ & & \\
\hline
\end{tabular}

** Significativo a $1 \%$ de probabilidade pelo Teste $\mathrm{F}$.

\subsection{Características culinárias}

De acordo com a análise de variância, a interação entre as etnovariedades e as épocas de colheita foi significativa $(p<0,01)$ (Tabela 5$)$, evidenciando que a época de colheita influenciou o tempo de cocção.

Quanto ao tempo de cocção, foram observadas diferenças significativas das etnovariedades dentro de cada época de colheita, sendo que as quatro etnovariedades estudadas apresentaram as menores médias de cocção aos seis meses pós-plantio (Figura 3).

Os resultados indicam que as etnovariedades analisadas neste estudo podem ser colhidas aos seis e oito meses após o plantio. Já Fialho et al. (2002), em estudos com 11 variedades de mandioca, observaram menor tempo de cozimento (inferior a $30 \mathrm{~min}$ ) aos 10 meses após o plantio, enquanto Souza (2007) observou que as raízes colhidas aos nove meses apresentaram menor tempo de cozimento que aquelas colhidas aos 18 meses, 
Cacau branca

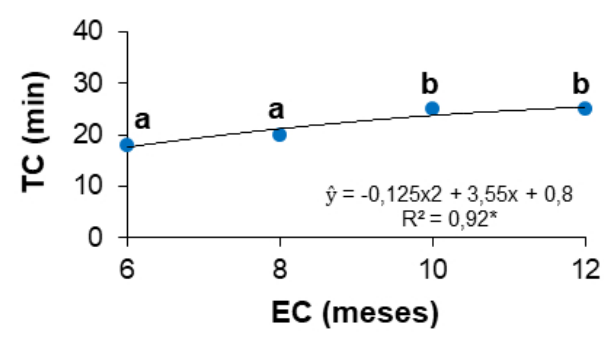

Cacau amarela

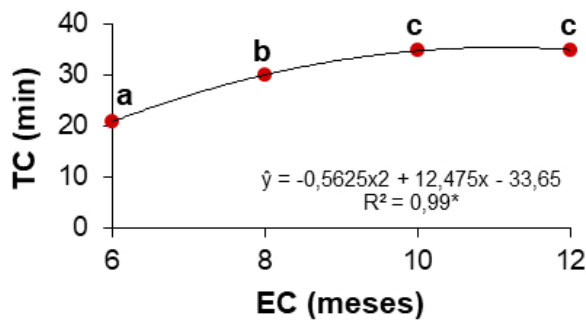

Cacau roxa

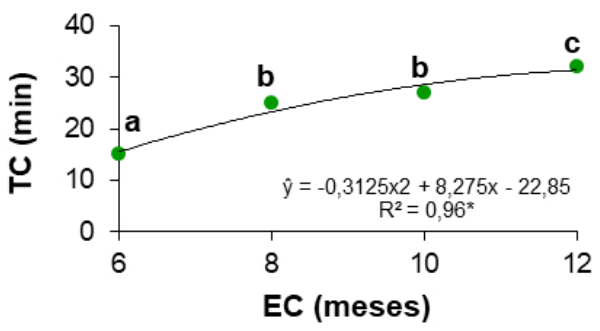

Mandioca pão

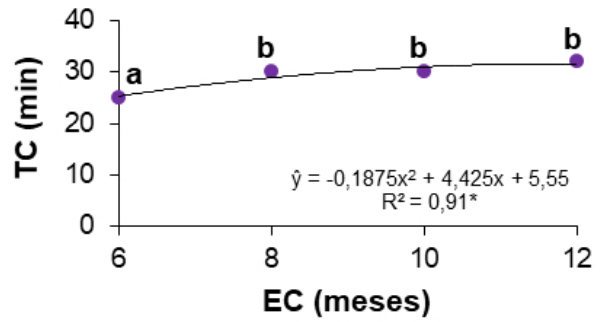

Figura 3. Estimativa do tempo de cocção (TC) das quatro etnovariedades de mandioca em quatro épocas de colheita (EC): seis, oito, 10 e 12 meses. Médias seguidas de letras minúsculas não diferem entre si pelo Teste de Tukey a 5\% de probabilidade; *Significativo a $5 \%$ de probabilidade pelo Teste $\mathrm{F}$.

ressaltando ainda que plantas que permanecem mais tempo no campo apresentam maior porcentagem de fibras, aumentando o tempo de cozimento.

O tempo de cocção variou de bom (11 a 20 min) a ruim (> $30 \mathrm{~min}$ ) entre as etnovariedades, sendo que a CR apresentou o menor tempo de cozimento (15 min), aos seis meses, e CA, o maior tempo (35 min), aos 10 e 12 meses (Tabela 6). Em comparação com outros estudos, com distintas variedades de mandioca, os tempos de cozimento obtidos nesta análise foram superiores ao máximo obtido por Borges et al. (2002), 30 minutos; inferiores ao máximo obtido por Mezette et al. (2009), 52 minutos, e inferiores ao mínimo observado por Talma et al. (2013), 17 minutos.

A etnovariedade CB apresentou cozimento que variou entre 'bom' e 'regular' nas quatro épocas de análise, obtendo, portanto, menor média (22 min) de tempo de cocção, seguida pela CR (25 min), MP (29 min) e CA (30 min). A média geral de cozimento das quatro etnovariedades avaliadas foi de 27 minutos, o que, segundo Pereira et al. (1985), é um tempo de cozimento regular, sendo então consideradas adequadas para variedades de mesa (inferior a $30 \mathrm{~min}$ ).

A permanência das plantas no campo, para as quatro etnovariedades avaliadas, ocasionou um aumento crescente no tempo de cozimento e consequente mudança na escala de tempo de cocção, passando das classes 'bom' e 'regular' (seis, oito e 10 meses) para classe 'ruim', aos 12 meses (Figura 3). Ponte (2008), estudando épocas de colheitas de variedades de mandioca, também observou uma relação crescente linear do tempo de cozimento em função das épocas de colheita.

Raízes cozidas de boa qualidade, entre outras características, devem apresentar massa não encaroçada, plástica e não pegajosa (LORENZI, 1994). Neste estudo, a etnovariedade CB apresentou estas características aos oito meses de avaliação e CA e MP, aos seis meses, obtendo, portanto, maior nota de classificação (10) e, consequentemente, excelente padrão de massa cozida (Tabela 6).

Quando analisada a média do padrão de massa cozida das etnovariedades, a CB e a CR apresentaram-se pouco encaroçadas, plásticas e não pegajosas, obtendo maior nota (9) de classificação, seguida por MP (8) e CA (7). Vale destacar que a etnovariedade CA apresentou a menor nota de padrão de massa cozida e a maior média de tempo de cozimento (30 min), corroborando com Lorenzi (1994), que destaca que o tempo de cozimento correlaciona-se com a qualidade da massa cozida, sendo que quanto maior esse tempo, pior a massa obtida.

\subsection{Deterioração das raízes pós-colheita}

As raízes das etnovariedades avaliadas exibiram deterioração pós-colheita, apresentando escala que variou entre 1 (sem deterioração) e 5 (mais de 60\% das raízes deterioradas). Todas as etnovariedades foram suscetíveis à deterioração quando armazenadas em condição ambiente 
Características morfológicas e culinárias de etnovariedades de mandioca de mesa em diferentes épocas de colheita Pedri, E. C. M. et al.

Tabela 6. Classificação de massa cozida das etnovariedades Cacau branca, Cacau roxa, Cacau amarela e Mandioca pão em quatro épocas de colheita.

\begin{tabular}{ccccc} 
& \multicolumn{4}{c}{ Épocas de colheita } \\
\cline { 2 - 5 } Etnovariedades & $\mathbf{6}$ meses & $\mathbf{8}$ meses & $\mathbf{1 0}$ meses & $\mathbf{1 2}$ meses \\
Cacau branca & 9 & 10 & 8 & 8 \\
Cacau roxa & 9 & 8 & 9 & 9 \\
Cacau amarela & 10 & 9 & 4 & 6 \\
Mandioca pão & 10 & 8 & 9 & 6 \\
\hline
\end{tabular}

Tabela 7. Avaliação da deterioração pós-colheita das raízes das etnovariedades avaliadas em quatro épocas de colheita.

\begin{tabular}{ccccc} 
& \multicolumn{5}{c}{ Épocas de colheita } \\
\cline { 2 - 5 } Etnovariedades & $\mathbf{6}$ meses & $\mathbf{8}$ meses & $\mathbf{1 0}$ meses & $\mathbf{1 2}$ meses \\
Cacau branca & 5 & 4 & 4 & 5 \\
Cacau roxa & 5 & 3 & 3 & 4 \\
Cacau amarela & 2 & 2 & 1 & 1 \\
Mandioca pão & 2 & 2 & 1 & 2 \\
\hline
\end{tabular}

por quatro dias após a colheita, porém a CA e a MP foram as que apresentaram menor deterioração (Tabela 7), sendo, portanto, recomendadas para plantios que visem à comercialização.

A etnovariedade CA apresentou até $20 \%$ de raízes deterioradas nas duas primeiras épocas de avaliação e 100\% de raízes conservadas aos 10 e 12 meses (Tabela 7), período em que também se apresentou dificuldade para destacar película e córtex. Esses resultados corroboram com Ramos (2007), que relata que, do ponto de vista pós-colheita, películas e córtex mais aderidos às raízes são preferidos por aumentar a proteção contra danos externos, obtendo maior conservação das raízes.

As etnovariedades CA e MP apresentaram até $80 \%$ e $100 \%$ das raízes conservadas aos 10 e 12 meses pós-plantio, indicando que a conservação das raízes em temperatura ambiente foi adequada, não ocasionando danos na qualidade das mesmas. Para as etnovariedades CB e CR, a escala variou de 3 (20\% a 40\% das raízes deterioradas) a 5 (mais de $60 \%$ de raízes deterioradas) entre as épocas de colheita, apresentando-se como inapropriadas para o consumo humano após quatro dias de armazenamento. Essa restrição está de acordo com Ramos et al. (2013), que apontam que raízes deterioradas apresentam mudança no sabor, não sendo apropriadas para a comercialização e o consumo.

\section{Conclusões}

As etnovariedades de mandioca Cacau branca, Cacau roxa, Cacau amarela e Mandioca pão apresentam variação fenotípica quanto às características 'cor da película da raiz', 'cor do córtex' e 'cor da polpa'.

Quanto às características 'tempo de cocção' e 'qualidade da massa cozida', as raízes das quatro etnovariedades, colhidas aos seis e oito meses pós-plantio, apresentaram-se ideais para o consumo de mesa.

As etnovariedades Cacau amarela e Mandioca pão são as mais indicadas para cultivos que visem à comercialização, pois apresentaram, em todas as épocas de colheita, menor susceptibilidade à deterioração.

\section{Agradecimentos}

À Fundação de Amparo à Pesquisa do Estado de Mato Grosso (FAPEMAT), pelo financiamento do projeto processo n. ${ }^{\circ}$ 484.514/2011; à Coordenação de Aperfeiçoamento de Pessoal de Nível Superior (CAPES), pela concessão de bolsa à primeira autora, e à Secretaria de Educação do Estado de Mato Grosso (SEDUC/MT), pela concessão de licença para qualificação profissional à terceira autora.

\section{Referências}

ALVARES, C. A.; STAPE, J. L.; SENTELHAS, P. C.; GONÇALVES, J. L. M.; SPAROVEK, G. Koppen's climate classification map for Brazil. Meteorologische Zeitschrift, v. 22, n. 6, p. 711-728, 2013. http://dx.doi.org/10.1127/0941-2948/2013/0507.

BOOTH, R. H. Storage of fresh cassava (Manihot esculenta). I. Post-harvest deterioration and its control. Experimental Agriculture, v. 12, n. 02, p. 103-111, 1976. http://dx.doi. org/10.1017/S001447970000716X

BORGES, M. F.; CARVALHO, V. D.; FUKUDA, W. M. G. Efeito de tratamento térmico na conservação pós-colheita de raízes de mandioca (Manihot esculenta Crantz) de mesa. Revista Brasileira de Mandioca, v. 11, n. 1, p. 7-18, 1992.

BORGES, M. F.; FUKUDA, W. M. G.; ROSSETTI, A. G. Avaliação de variedades de mandioca para consumo humano. Pesquisa Agropecuária Brasileira, v. 37, n. 11, p. 1559-1565, 2002. http:// dx.doi.org/10.1590/S0100-204X2002001100006.

CHISTÉ, R. C.; COHEN, K. O. Estudo do processo de fabricação da farinha de mandioca. Belém: Embrapa Amazônia Oriental. 2006. 76 p. (Documentos 267).

CRUZ, C. D. GENES: a software package for analysis in experimental statistics and quantitative genetics. Acta Scientiarum, v. 35, n. 3, p. 271-276, 2013. http://dx.doi.org/10.4025/actasciagron. v35i3.21251

EMPRESA BRASILEIRA DE PESQUISA AGROPECUÁRIA EMBRAPA. Sistema brasileiro de classificação de solos. 3 . ed. Rio de Janeiro: Embrapa Solos, 2013.

FARALDO, M. I. F.; SILVA, R. M.; ANDO, A.; MARTINS, P. S. Variabilidade genética de etnovariedades de mandioca em regiões geográficas do Brasil. Scientia Agrícola, v. 57, n. 3, p. 499-505, 2000. http://dx.doi.org/10.1590/S0103-90162000000300020.

FENIMAN, C. M. Caracterização de raízes de mandioca (Manihot esculenta Crantz) do cultivar IAC 576-70 quanto à 
Características morfológicas e culinárias de etnovariedades de mandioca de mesa em diferentes épocas de colheita Pedri, E. C. M. et al.

cocção, composição química e propriedades do amido em duas épocas de colheita. 2004. 83 f. Dissertação (Mestrado em Ciências)--Escola Superior de Agricultura Luiz de Queiroz, Universidade de São Paulo, Piracicaba, 2004.

FIALHO, J. F.; FUKUDA, W. M. G.; PEREIRA, A. V.; JUNQUEIRA, N. T. V.; GOMES, A. C. Avaliação de variedades de mandioca de mesa nas condições de cerrado do Distrito Federal. Planaltina: Embrapa Cerrados, 2002. 20 p. (Boletim de Pesquisa e Desenvolvimento 73).

FUKUDA, W. M. G.; GUEVARA, C. L. Descritores morfológicos e agronômicos para a caracterização de mandioca (Manihot esculenta Crantz). Cruz das Almas: CNPMF, 1998. 38 p.

GUSMÃO, L. L.; MENDES NETO, J. A. Caracterização morfológica e agronômica de acessos de mandioca nas condições edafoclimáticas de São Luís, MA. Revista da Faculdade de Zootecnia, Veterinária e Agronomia, v. 15, n. 2, p. 28-34, 2008.

HENRIQUE, C. M.; PRATI, P.; SARMENTO, S. B. S. Alterações fisiológicas em raízes de mandioca minimamente processadas. Pesquisa \& Tecnologia, v. 7, n. 1, p. 1-7, 2010.

LORENZI, J. O. Variação na qualidade culinária das raízes de mandioca. Bragantia, v. 53, n. 2, p. 237-245, 1994. http://dx.doi. org/10.1590/S0006-87051994000200013.

MEZETTE, T. F.; CARVALHO, C. R. L.; MORGANO, M. A.; SILVA, M. G.; PARRA, E. S. B.; GALERA, J. M. S. V.; VALLE, T. L. Seleção de clones-elite de mandioca de mesa visando a características agronômicas, tecnológicas e químicas. Bragantia, v. 68, n. 3, p. 601-609, 2009. http://dx.doi.org/10.1590/S0006-87052009000300006.

OLIVEIRA, A. O.; LEONEL, M.; CABELLO, C.; CEREDA, M. P.; JANES, D. A. Metodologia para avaliação do tempo de cozimento e características tecnológicas associadas em diferentes cultivares de mandioca. Ciência e Agrotecnologia, v. 29, n. 1, p. 126-133, 2005. http://dx.doi.org/10.1590/S1413-70542005000100016.

OLIVEIRA, N. T.; ALVES, J. M. A.; UCHÔA, S. C. P.; RODRIGUES, G. S.; MELVILLE, C. C.; ALBUQUERQUE, J. A. A. Caracterização e identificação de clones de mandioca produzidos em Roraima para o consumo in natura. Revista Agro@ mbiente Online (Bergheim), v. 5, n. 5, p. 188-193, 2011. http://dx.doi.org/10.18227/19828470ragro.v5i3.624

OLIVEIRA, S. P.; VIANA, A. E. S.; MATSUMOTO, S. N.; CARDOSO JÚNIOR, N. S.; SEDIYAMA, T.; SÃO JOSÉ, A. R. Efeito da poda e de épocas de colheita sobre características agronômicas da mandioca. Acta Scientiarum. Agronomy, v. 32, n. 1, p. 99-108, 2010. http://dx.doi.org/10.4025/actasciagron.v32i1.922.

PEREIRA, A. S.; LORENZI, J. O.; VALLE, T. L. Avaliação do tempo de cozimento e padrão de massa cozida em mandiocas de mesa. Revista Brasileira de Mandioca, v. 4, n. 1, p. 27-32, 1985.

PONTE, C. M. A. Épocas de colheita de variedades de mandioca. 2008. 93 f. Dissertação (Mestrado em Agronomia)--Universidade Estadual do Sudoeste da Bahia, Vitória da Conquista, 2008.
RAMOS, P. A. S. Caracterização morfológica e produtiva de nove variedades de mandioca cultivadas no sudoeste da Bahia. 2007. 60 f. Dissertação (Mestrado em Fitotecnia)-Universidade Federal de Viçosa, Viçosa, 2007.

RAMOS, P. A.; SEDIYAMA, T.; VIANA, A. E. S.; PEREIRA, D. M.; FINGER, F. L. Efeito de inibidores da peroxidase sobre a conservação de raízes de mandioca in natura. Brazilian Journal of Food Technology, v. 16, n. 2, p. 116-124, 2013. http://dx. doi. org/10.1590/S1981-67232013005000018.

Ribeiro, A. C.; GuimarÃES, P. T. G.; AlvareZ, V. H. Recomendações para o uso de corretivos e fertilizantes em minas gerais: $5^{\circ}$ aproximação. Viçosa: UFV, 1999. 359 p.

SILVA, K. N.; VIEIRA, E. A.; FIALHO, J. F.; CARVALHO, L. J. C. B.; SILVA, M. S. Potencial agronômico e teor de carotenoides em raízes de reserva de mandioca. Ciência Rural, v. 44, n. 8, p. 1348-1354, 2014. http://dx.doi.org/10.1590/0103-8478cr20130606.

SOARES, M. R. S. Características de variedades de mandioca em função de épocas de colheita. 2011. 110 f. Dissertação (Mestrado em Agronomia)--Universidade Estadual do Sudoeste da Bahia, Vitória da Conquista, 2011.

SOUZA, M. J. L. Manejo da irrigação, épocas de colheita e efeito do cloreto de mepiquat sobre características agronômicas da mandioca. 2007. 68 f. Dissertação (Mestrado em Agronomia)--Universidade Estadual do Sudoeste da Bahia, Vitória da Conquista, 2007.

TALMA, S. V.; ALMEIDA, S. B.; LIMA, R. M. P.; VIEIRA, H. D.; BEBERT, P. A. Tempo de cozimento e textura de raízes de mandioca. Brazilian Journal of Food Technology, v. 16, n. 2, p. 133-138, 2013. http://dx.doi.org/10.1590/S1981-67232013005000016.

VIEIRA, E. A.; FIALHO, J. F.; SILVA, M. S.; FUKUDA, W. M. G.; FALEIRO, F. G. Variabilidade genética do banco de germoplasma de mandioca da Embrapa cerrados acessada por meio de descritores morfológicos. Científica, Jaboticabal, v. 36, n. 1, p. 56-67, 2008.

VIEIRA, E. A.; FIALHO, J. F.; SILVA, M. S.; FUKUDA, W. M. G.; SANTOS FILHO, M. O. S. Comportamento de genótipos de mandioca de mesa no Distrito Federal. Revista Ciência Agronômica, v. 40, n. 1, p. 113-122, 2009.

VÍTOR, L. A.; ARCHANGELO, E. R.; TEIXEIRA JÚNIOR, T.; SOARES, M. M.; VIEIRA, F. L.; MADEIRO, I. I. C. Produtividade e qualidade das raízes da mandioca em função de diferentes épocas de colheita. Agri-Environmental Sciences, v. 1, n. 2 , p. 67-72, 2015.

WHEATLEY, C. C. Conservación de raíces de yuca en bolsas de polietileno. Cali: Centro Internacional de Agricultura Tropical, 1987.

WHEATLEY, C.; GOMEZ, G. Evaluation of some quality characteristics in cassava storage roots. Qualitas Plantarum Plant Foods for Human Nutrition, v. 35, n. 2, p. 121-129, 1985. http://dx.doi. org/10.1007/BF01092127. 